\title{
Bilingual access of homonym meanings: Individual differences in bilingual access of homonym meanings
}

(Received: September 15, 2013; final revision received: August 1, 2014; accepted: August 10, 2014; first published online 4 November 2014)

\begin{abstract}
The goal of the present study was to identify the cognitive processes that underlie lexical ambiguity resolution in a second language (L2). We examined which cognitive factors predict the efficiency in accessing subordinate meanings of L2 homonyms in a sample of highly-proficient, Spanish-English bilinguals. The predictive ability of individual differences in (1) homonym processing in the L1, (2) working memory capacity and (3) sensitivity to cross-language form overlap were examined. In two experiments, participants were presented with cognate and noncognate homonyms as either a prime in a lexical decision task (Experiment 1) or embedded in a sentence (Experiment 2). In both experiments speed and accuracy in accessing subordinate meanings in the L1 was the strongest predictor of speed and accuracy in accessing subordinate meanings in the L2. Sensitivity to cross-language form overlap predicted performance in lexical decision while working memory capacity predicted processing in sentence comprehension.
\end{abstract}

Keywords: bilingualism, ambiguity resolution, cross-language activation, transfer of skills

\section{Introduction}

Languages are replete with semantic ambiguities; any given word is likely to have multiple senses or meanings (i.e. homonyms, such as fast). During lexical access of ambiguous words, the multiple meanings are activated in parallel, causing competition that must be resolved for successful comprehension (Beretta, Fiorentino \& Poeppel, 2005; Chwilla \& Kolk, 2003; Dixon \& Twilley, 1999; Gottlob, Goldinger, Stone \& Van Orden, 1999; Hino, Lupker \& Pexman, 2002; Klepousniotou, 2002; Nievas \& Mari Beffa, 2002; Pexman \& Lupker, 1999; Rodd, Gaskell \& Marslen Wilson, 2002). The time it takes to resolve this competition and select the target meaning depends on the relative frequency of the target meaning and the degree to which it is biased by context. When the target meaning is the low-frequency, subordinate meaning of a homonym, its activation will lag behind that of the dominant. As a result, in neutral contexts, first-pass processing time of the homonym will be similar to that of a non-homonym. The cost associated with selecting the subordinate meaning is typically observed after the initial encounter with the homonym, either through inflated processing time of later segments of the sentence or through regressions back to the homonym (Duffy, Morris \& Rayner, 1988). When the subordinate meaning is biased by context, on the other hand, it accelerates its activation and it competes directly with the dominant meaning before lexical access is completed. As a consequence, processing times during the initial encounter with the homonym is inflated: this has been termed the "subordinate bias effect" (Duffy et al., 1988).

There are important individual differences in the ability to resolve competition between the multiple meanings of homonyms and it is a hallmark of skilled reading (Gernsbacher, 1990, 1991, 1997a, 1997b; Gernsbacher \& Faust, 1995; Gernsbacher \& St John, 2001; Gernsbacher, Robertson \& Werner, 2001). Although proficient L2 readers are able to activate the multiple meanings of L2 homonyms (Frenck-Mestre \& Prince, 1997), the cognitive demands of resolving this competition are likely to be greater than for native readers since even high-proficiency bilinguals have less-automatized lexical processes (Segalowitz \& Hulstijn, 2005). This, in turn, may impede the formation of accurate representations of L2 homonyms in long-term memory since adult L2 learners find it harder to learn homonyms than nonhomonyms (Degani \& Tokowicz, 2010).

The focus of the present experiments was to investigate the cognitive factors that predict how efficiently highproficiency bilingual readers access subordinate meanings of L2 homonyms. Three individual differences measures were examined: (1) relative speed/accuracy of accessing homonym meanings in the L1, (2) working memory capacity in the L1 and (3) the relative influence of cross-language lexical form-overlap in recognizing L2 words. This latter factor is original to this study and described in more detail below. The three individual

Address for correspondence:

Ana Beatriz Arêas da Luz Fontes, Universidade Federal do Rio Grande do Sul, Porto Alegre, RS - Brazil

aninhafontes@icloud.com 
differences components were examined in both primed lexical decision (Experiment 1) and in sentence context (Experiment 2).

\section{Access of homonym meanings in the L1}

Research has shown that $\mathrm{L} 1$ reading comprehension is a strong predictor of L2 reading comprehension (Van Gelderen, Schoonen, Stoel, De Glopper, Hulstijn, 2007; Van Gelderen, Schoonen, De Glopper, Hulstijn, Simis, Snellings \& Stevenson, 2004). According to Walter (2007) comprehension skills are not transferred per se, but rather the same, cognitive-general skills supporting comprehension are differentially accessed in an L1 compared to an L2. According to the Structure Building Framework (Gernsbacher, 1991), the two cognitive general skills that support comprehension are enhancement and suppression. Enhancement is the ability to quickly activate relevant representations from long-term memory while suppression is the ability to deactivate representations that are not relevant. For example, comprehension of the sentence "He dug with a SPADE" requires enhancement of memory nodes relating to the "shovel" meaning, while simultaneously suppressing nodes related to the competing "playing cards" meaning. Gernsbacher and colleagues have demonstrated that these skills operate across different types of comprehension and beyond language-based modalities, supporting the claim that they are in fact cognitive-general skills (Gernsbacher, Varner \& Faust, 1990). In the present study we hypothesized that individual differences in suppression and enhancement would be demonstrated by a strong relationship between access of homonym meanings in the L1 and L2 in both single-word and sentence contexts.

\section{Working memory capacity}

Individual differences in working memory capacity (WMC) have been implicated in the activation of homonym meanings and inhibition of competing meanings (however, there is debate regarding which of these processes is specifically influenced by WMC). For example, Miyake, Just and Carpenter (1994) observed that readers with lower WMC took longer to process sentences in which the subordinate meaning of a homonym was favored towards the end of the sentence (e.g., "Since Ken really liked the boxer, he took a bus to the nearest pet store to buy the animal"), suggesting that they were not able to sustain activation of the subordinate meaning.

Gunter, Wagner and Friederici (2003), on the other hand, found evidence supporting WMC effects on inhibition of homonym meanings. In that study, event related potentials (ERPs) were collected from Germanspeaking participants with high and low WMC while they read sentences that required a switch between the two homonym meanings. These sentences consisted of an initial noun phrase containing an ambiguous word (e.g., Der Ball wurde vom [the ball was]), followed by a noun related to either the dominant or subordinate meaning (e.g., Spieler [player] or Tänzer [dancer]). Finally, the sentences included a verb that disambiguated the homonym in German (e.g., geworfen [thrown]). For readers with high WMC, the N400 component showed a switch cost irrespective of the direction of the switch (going from dominant to subordinate, or from subordinate to dominant). This suggests that, prior to the switch, the irrelevant meaning had been inhibited. The N400 component of readers with low WMC, on the other hand, did not reflect a cost when switching from the subordinate to dominant meaning, suggesting that they had not inhibited the dominant meaning prior to the switch.

In another study, individual differences in short-term memory span (measured by digit-span tasks) were found to influence bilinguals' processing of homonyms (Arêas da Luz Fontes \& Schwartz, 2011). In that study, SpanishEnglish bilinguals read all-English sentences that biased the subordinate meaning of homonyms (e.g., "Her ideas were always creative and novel") and then judged whether a follow-up target word (e.g., "BOOK" or "NEW") was related in meaning to that sentence (e.g., answer "NO" to "BOOK). Half of the homonyms had dominant meanings that were also cognates with the non-target language, Spanish (e.g., the "book" meaning of the cognate homonym novel/novela). Bilinguals with shorter memory span showed a cost in rejecting targets related to the dominant meaning of noncognate homonyms as well as a speed-accuracy trade-off for cognate homonyms. Participants with higher span showed no costs in their performance.

The study by Arêas da Luz Fontes and Schwartz (2011) used a measure of short-term memory that only required storage of information. In the present study we used the Daneman and Carpenter (1980) reading-span task, which requires maintaining words in short-term memory while comprehending sentences. We expected WMC to predict homonym processing time in sentence context but not in primed lexical decision, which does not place the same demands on simultaneous storage and comprehension.

\section{Effect of cognate status on $L 2$ lexical access}

Bilingual lexical access involves parallel activation of words from both languages (e.g., Dijkstra, Grainger \& Van Heuven, 1999; Gollan, Foster \& Frost, 1997; Kroll \& Stewart, 1994, Schwartz, Kroll \& Diaz, 2007). One of the most consistent findings from this research is cognate facilitation, which has been observed in isolated word recognition, translation, and picture naming (de Groot \& Keijzer, 2000; Dijkstra \& van Hell, 2003; Dijkstra, 
Miwa, Brummelhuis, Sappelli \& Baayen, 2010; Hoshino \& Kroll, 2008; Lemhöfer \& Dijkstra, 2004; Lemhöfer, Dijkstra \& Michel, 2004) as well as in sentence context (Elston-Güttler, 2000; Elston-Güttler, Gunter, Kotz, 2005; Libben \& Titone, 2009; Duyck, Van Assche, Drieghe \& Hartsuiker, 2007; Schwartz \& Kroll, 2006; Van Hell \& de Groot, 2008). The interpretation is that cognate facilitation arises from dual activation of lexical form and meaning.

Effects of cognate status have also been observed when there is incomplete overlap in meaning, as is the case for homonyms that have one cognate meaning across languages (e.g., novel/novela only share "book" meaning in English and Spanish). For example, in one study bilinguals were asked to generate sentences using the first homonym meaning that came to mind (e.g., use the word "novel" in a sentence). Bilinguals were more likely to generate a sentence using a cognate meaning of a homonym, even if that cognate meaning was a low-frequency meaning in the target language (e.g., the "serious" meaning of grave). Consequently, the relative frequency with which different homonym meanings were used diverged significantly from that reported in published, monolingual norms (Arêas da Luz Fontes \& Schwartz, 2010). Also, bilinguals show a greater cost in rejecting dominant meanings when these are cognates relative to noncognates (Schwartz, Yeh \& Shaw, 2008), suggesting increased competition from cross-language co-activation of the dominant meaning.

Homonym processing for bilinguals requires lexical representations that are detailed and precise in order to minimize competition from words across languages that may share a high degree of form but map on to distinct meanings. In research on monolingual readers the term "lexical quality" has been used to refer to word representations that are strong, precise and redundant (see Andrews, 2012, for a review). The precision of these highquality representations reduces the confusability of formsimilar words like "alter" and "altar". These studies have demonstrated that there is a significant range amongst adult readers in the quality of their underlying lexical representations (Andrews \& Bond, 2009; Andrews \& Lo, 2012; Bell \& Perfetti, 1994; Yap, Balota, Sibley \& Ratcliff, 2012). We assumed that the bilingual lexical expert would have representations that are both precise and robust, minimizing cross-language interference when meanings diverge while at the same time maximizing benefits when they converge. Performance from these readers would reflect greater facilitation when form-to- meaning mappings are consistent (e.g., recognizing unambiguous cognates) without sacrificing speed or accuracy when processing words in which form-to-meaning mappings are inconsistent (e.g., recognizing cognate homonyms).

In sum, we expected the predictive power of each individual differences measure to follow a distinct pattern. First, individual differences in accessing L1 homonym meanings, which reflect variation in the cognitive-general abilities of enhancement and suppression, would predict homonym processing in lexical decision as well as sentence comprehension. Second, individual differences in WMC would predict performance in the sentence comprehension task only, since it requires simultaneous storage and processing. Finally, individual differences in cognate effects would play a larger role in the lexical decision task, since effects of cross-language lexical form activation are greatest for words in isolation.

\section{Experiment 1}

In Experiment 1 we predicted facilitated access to cognate subordinate meanings of homonyms relative to noncognate meanings. Regarding individual differences, we predicted that access to subordinate meanings of cognate homonyms versus noncognate homonyms would be differentially influenced by the three individual difference factors being examined - 1) WMC, 2) access to L1 meanings and 3) magnitude of cognate effects. Access to cognate homonym meanings was expected to be influenced by access to L1 homonym meanings as well as individual differences in the magnitude of cognate effects. Access to noncognate homonym meanings was expected only to be influenced by access of homonym meanings in the L1. WMC was not expected to be a significant predictor because single word recognition is not particularly taxing on working memory resources. To test these hypotheses we used an English primed lexical decision paradigm, similar to that reported by FrenckMestre and Prince (1997).

\section{Methods}

\section{Participants}

110 Spanish-English bilinguals recruited from the English Speakers of Other Language (ESOL) courses and from the Introduction to Psychology courses at the University of Texas at El Paso (UTEP) participated in the study. After applying proficiency criteria for inclusion (detailed in next section), data from 31 participants (28.2\%) were excluded from analyses, leaving a sample of 79 .

\section{Assessing bilingualism and inclusion criteria.}

To ensure that participants were highly fluent in Spanish and that their proficiency in English was sufficient to be included in the study, we used two proficiency measures. As a subjective measure we used the self-assessed Language Experience and Proficiency Questionnaire (LEAP-Q) (Marian, Blumenfeld \& Kaushanaskaya, 2007). As an objective measure, we compared reaction times on the control conditions (i.e., non-cognate/ 
Table 1. Self-rated proficiency, objective proficiency and language background of the Spanish-English bilinguals in Experiment 1.

\begin{tabular}{|c|c|c|}
\hline \multicolumn{3}{|c|}{ Self-rated proficiency measures from LEAP-Q (scale of 1-10) } \\
\hline & Mean $(S D)$ & Mean $(S D)$ \\
\hline & Spanish & English \\
\hline Speaking & $8.8(1.4)$ & $7.2(2.0)$ \\
\hline Reading & $8.4(1.7)$ & $7.8(1.6)$ \\
\hline Comprehending & $9.0(1.1)$ & $7.9(1.6)$ \\
\hline \multicolumn{3}{|c|}{ Percentage of time reported exposed to each language } \\
\hline & Mean $(S D)$ & Mean $(S D)$ \\
\hline & Spanish & English \\
\hline Total exposure & $60.5(15.6)$ & $39.5(14.9)$ \\
\hline Reading & $53(17.3)$ & $36.2(18.8)$ \\
\hline Speaking & $69(21.3)$ & $31(19.1)$ \\
\hline \multicolumn{3}{|c|}{ Age of acquisition of each language } \\
\hline & Mean $(S D)$ & Mean $(S D)$ \\
\hline & Spanish & English \\
\hline & $1.1(.92)$ & $7.0(4.9)$ \\
\hline \multicolumn{3}{|c|}{ Mean decision latency on control trials of the lexical decision task } \\
\hline & Mean $(S D)$ & Mean (SD) \\
\hline & Spanish & English \\
\hline & $1021.5(287.1)$ & $850.7(212.9)$ \\
\hline
\end{tabular}

non-homonym primes) of the lexical decision tasks in both English and Spanish. Faster reaction times in either language reflected dominance in that language.

We first included in the analyses participants who reported Spanish as their dominant language, and whose ratings in speaking, reading, and comprehending were higher in Spanish than English $(n=76)$. Next, we included participants who reported English to be their dominant language, but rated themselves higher in Spanish than English $(\mathrm{n}=1)$. Finally, we included participants whose objective measure of proficiency indicated greater proficiency in Spanish than English $(n=3)$.

\section{Proficiency data}

Data from the LEAP-Q are summarized in Table 1. Participants reported acquiring English later than Spanish $t(73)=-10.11, p<.01$. The average proficiency rating was higher in Spanish $(M=8.7)$ than English $(M=6.4), t(75)=4.9, p<.01$. Additionally, participants were more exposed to Spanish $(M=60 \%)$ than to English $(M=40 \%), t(78)=6.25, p<.01$; read more in Spanish $(M=53 \%), t(76)=4.70, p<.01$; and spoke more in Spanish $(M=70 \%), t(76)=8.8, p<.01$. Although participants' subjective measure of proficiency suggested greater proficiency in Spanish, their objective measure of proficiency suggested otherwise. Participants were faster to recognize target words that were related to noncognate, non-homonym primes in English $(M=851)$ than Spanish $(M=1,021), \quad t(69)=-5.35, \quad p<.01$. However, this finding needs to be interpreted with caution because posthoc analyses showed that Spanish targets were longer $(M=6.3)$ than English targets $(M=5.3), t(158)=-3.7$, $p<.01$.

\section{Materials}

\section{Initial norming procedures}

To ensure that bilingual participants would be familiar with the subordinate meanings of the English homonyms, a set of 125 English homonyms was normed with responses from a group of 35 students from the same target population as the critical experiments. Bilinguals were presented with the individual homonyms and asked to write down all the meanings of that word that came to mind. English homonyms for which the subordinate meaning was generated less than $30 \%$ of the time and the dominant meaning was generated more than $70 \%$ of the time were selected. Participants were then given the list of homonyms with their dictionary meanings, and asked to check which meanings they recognized. Only homonyms with subordinate meanings that were recognized by at 
Table 2. Frequency and length of the primes and targets of the English primed lexical decision task of Experiment 1 .

\begin{tabular}{|c|c|c|c|c|}
\hline & \multicolumn{2}{|c|}{ Related homonyms } & \multicolumn{2}{|c|}{ Unrelated homonym } \\
\hline & Cognate & Noncognate & Cognate & Noncognate \\
\hline & Mean $(S D)$ & Mean $(S D)$ & Mean $(S D)$ & Mean (SD) \\
\hline Prime Celex frequency & $61.6(59.3)$ & $87.6(108.8)$ & $72.4(88.4)$ & $75.2(121.7)$ \\
\hline Prime length* & $5.3(1.7)$ & $4.5(.93)$ & $5.2(1,2)$ & $4.7(1.0)$ \\
\hline Target (dominant meaning) Celex frequency & $99.6(102.5)$ & $102.7(99.3)$ & $70.8(85.0)$ & $100.4(94.0)$ \\
\hline Target (dominant meaning) length* & $5.3(1.7)$ & $4.3(.94)$ & $5.8(1.7)$ & $4.7(1.2)$ \\
\hline Target (subordinate meaning) Celex frequency & $69.8(89.9)$ & $84.5(79.3)$ & NA & NA \\
\hline \multirow[t]{4}{*}{ Target (subordinate meaning) length } & $5.8(1.6)$ & $5.3(1.6)$ & NA & NA \\
\hline & \multicolumn{2}{|c|}{ Related non-homonyms } & \multicolumn{2}{|c|}{ Unrelated non-homonyms } \\
\hline & Cognate & Noncognate & Cognate & Noncognate \\
\hline & Mean (SD) & Mean (SD) & Mean (SD) & Mean (SD) \\
\hline Prime Celex frequency & $55.8(61.9)$ & $68.9(76.0)$ & $41.7(65.3)$ & $48.9(38.1)$ \\
\hline Prime length* & $6.2(1.5)$ & $4.9(1.6)$ & $5.9(1.3)$ & $6.2(1.4)$ \\
\hline Target Celex frequency & $163.0(212.1)$ & $125.8(169.3)$ & $163.3(212.1)$ & $133.2(175.5)$ \\
\hline Target length & $5.1(1.5)$ & $5.3(1.6)$ & $5.0(1.4)$ & $5.3(1.3)$ \\
\hline
\end{tabular}

least $80 \%$ of participants were included. After applying the above criteria, 88 polarized English homonyms were selected.

Because the pool of words had already been much reduced $(\mathrm{N}=88)$, syntactically ambiguous items were allowed in the list, but we ensured that they were equally represented across the noncognate $(n=15)$ and cognate conditions $(\mathrm{n}=13)$.

To distinguish objectively between cognates and noncognates within the English stimuli, we used the graphemic similarity algorithm developed by Van Orden (1987). This index measures how orthographically similar two words are - in this case the English homonyms and their Spanish translations. Word pairs for which the graphemic similarity quotient exceeded 0.5 (with a possible range from 0.0 to 1.0 ) were classified as cognates (e.g., arm/arma, letter/letra, cabinet/gabinete, cane/caña).

\section{Homonym prime-target pairs $(n=80)$}

Polarized homonyms served as prime words. Half of these were cognates with Spanish (cabinet/gabinete) with cognate subordinate meanings (e.g., "group of advisors" meaning), and half were noncognates (chest/cofre). Noncognate and cognate homonyms were matched in length, frequency, and part of speech. For each homonym prime, two targets were selected: one related to the dominant meaning (e.g., cabinet-KITCHEN; chestHAIR) and the other related to the subordinate meaning (e.g., cabinet-ADVISORS; chest-TREASURE). Targets were matched in length, frequency and part of speech.
Prime-target strength of association was also matched across the two homonym conditions based on published norms (Nelson, McEvoy \& Schreiber, 1998). See Table 2 for a summary of lexical properties.

For the unrelated prime-targets pairs, 20 targets used in the critical related condition were randomly selected to serve as targets in the unrelated condition. These targets were paired with unrelated homonym primes that were either cognates or noncognates. To ensure that participants saw any given target word only once, two experimental running lists were created. The overall frequency and length of the primes in the unrelated condition matched the overall frequency and length of the primes in the related condition.

\section{Non-homonym prime-target pairs $(n=80)$}

Control pairs were created by selecting non-homonym prime words that matched the overall length, frequency, and part of speech of the homonym primes described above. Half were cognates with Spanish and half were noncognates. Non-homonym primes were paired with either related or unrelated targets. Related targets were selected from published association norms (Nelson et al., 1998) and the strength of association between these targets and their non-homonym primes was matched with the strength of association between the homonym primes and their targets. Unrelated pairs were created for the control condition by pairing 20 randomly selected targets with unrelated non-homonym primes that were either cognates or noncognates. Unrelated primes were matched in overall length and frequency with primes from the 
Table 3. Examples of critical English word stimuli used in Experiment 1.

\begin{tabular}{lll}
\hline \hline & Related pairs & Unrelated pairs \\
\hline $\begin{array}{l}\text { Noncognate homonym condition } \\
\text { Target: dominant meaning }\end{array}$ & & \\
$\begin{array}{l}\text { Target: subordinate meaning } \\
\text { Cognate homonym condition }\end{array}$ & $\begin{array}{l}\text { chest-HAIR } \\
\text { chest-TREASURE }\end{array}$ & husky-TREASURE \\
Target: dominant meaning & & \\
Target: subordinate meaning & cabinet-KITCHEN & panel-KITCHEN \\
Noncognate non-homonym condition & cabinet-ADVISORS & panel-ADVISORS \\
Cognate non-homonym condition & breath-LUNG & painting-LUNG \\
\hline \hline
\end{tabular}

related condition. See Table 3 for examples of the primetarget pairs used in Experiment 1.

\section{Nonword prime-target pairs $(n=200)$}

For the nonword pairs, nonword targets were either paired with a homonym prime (e.g., left-HICE) or with a nonhomonym prime (clay-NIST). The stimulus word-set was divided into two different lists of 200 prime-target pairs.

\section{Individual differences measures}

\section{Working memory capacity (WMC)}

A Spanish version of the Reading Span task (Daneman and Carpenter, 1980) was used to assess participants' WMC during reading comprehension. Participants were required to read aloud a set of unrelated sentences (13 to 16 words in length) without pausing between sentences. At the end of each set of sentences, participants were asked to recall the last word of each sentence.

Participants read five blocks of sentences of each set size (two to six sentences per block), or until the participant failed to recall at least three out of five blocks from a particular set size. Participants' WMC was calculated by counting the highest number of correctly recalled (last) words of at least three blocks of sentences within a given set. If only two blocks were correctly recalled in the next set size, then participants received half a point. For example, if participants correctly recalled at least three blocks of (last) words within the two-sentence set, and failed to recall at least three blocks of the threesentence set, then his/her span was coded as two. However, if the participant additionally recalled two blocks of the three-sentence sentence, then he/she received half of a point and his/her span was coded as 2.5. Span scores ranged from one to four and averaged 2.01, indicating that participants fell under the mid-span category.

\section{Meaning access in the L1}

To measure bilinguals' efficiency in accessing subordinate meanings of homonyms in the L1, polarized Spanish homonyms were presented in a Spanish primed lexicaldecision task. On critical trials, the primes were Spanish noncognate homonyms $(\mathrm{n}=40)$ and the follow-up targets were either related to the subordinate [e.g., guarnición (garnish/trimming) - ADORNO] or dominant meaning [e.g., guarnición - ARROZ (rice)] of the homonym. Control pairs $(\mathrm{n}=40)$ were created by replacing homonym primes with an unrelated control word [e.g., murciélago (bat) - ARROZ; murciélago - ADORNO]. Related and unrelated prime-target filler pairs $(\mathrm{n}=40)$ were also included in the stimulus list so that the presence of a homonym could not cue participants that the followup target would be a word. Non-word targets were paired with either a homonym $(\mathrm{n}=60)$ or a non-homonym $(\mathrm{n}=60)$ prime.

\section{Measuring impact of cognate status on lexical access}

Performance data from the related, non-homonym trials on the English task were used to derive a score reflecting the impact of lexical form overlap (i.e., the cognate status of the target word) on participants' lexical access. This was a difference score, calculated by subtracting reaction times and error rates on cognate trials from reaction times and error rates on noncognate trials [(noncognate) (cognate)]. Therefore, the larger the observed difference score, the larger the facilitation from cognate status.

\section{Procedure}

Participants first completed the primed lexical-decision task in English. A trial began with a center fixation point, followed by a forward mask for 500 milliseconds (ms). The prime was then presented in lowercase for $100 \mathrm{~ms}$ and replaced immediately by the target, presented in capital letters. The target remained displayed for $3000 \mathrm{~ms}$ or until the participant's response. The task was self-paced. "Yes" responses were made with the right hand and "No" responses were made with the left hand. Participants then completed the same task in Spanish. 
Table 4. Participants' mean reaction times and error rates on the English primed lexical decision task.

\begin{tabular}{|c|c|c|c|c|c|c|c|c|c|c|}
\hline \multicolumn{11}{|c|}{ Reaction Times } \\
\hline & \multicolumn{4}{|c|}{ Unrelated } & \multicolumn{6}{|c|}{ Related } \\
\hline & & & & & & & & Homc & nym & \\
\hline & \multicolumn{2}{|c|}{ Non-homonym } & \multicolumn{2}{|c|}{ Homonym } & \multicolumn{2}{|c|}{ Non-homonym } & \multicolumn{2}{|c|}{ Non-cognate } & \multicolumn{2}{|c|}{ Cognate } \\
\hline & Non-cognate & Cognate & Non-cognate & Cognate & Non-cognate & Cognate & $\mathrm{D}$ & $\mathrm{S}$ & $\mathrm{D}$ & $\mathrm{S}$ \\
\hline Mean & 922 & 920 & 907 & 915 & 849 & 841 & 826 & 891 & 872 & 910 \\
\hline SD & 235 & 229 & 294 & 217 & 211 & 207 & 210 & 244 & 225 & 206 \\
\hline \multicolumn{11}{|c|}{ Error Rates } \\
\hline Mean & 7.9 & 7.8 & 7.2 & 8.2 & 4.7 & 2.2 & 3.3 & 6.5 & 5.1 & .56 \\
\hline SD & 13.3 & 13.2 & 13.1 & 11.9 & 6.9 & 3.8 & 5.3 & 10.7 & 5.7 & .70 \\
\hline
\end{tabular}

Next, participants completed the Spanish reading span task. A trial started with a fixation point, followed by the presentation of the sentences. Sentences were presented immediately after each other, without a pause between them. The experimenter pressed the space bar to show the participant each sentence, one at a time, thus controlling the pace of presentation of the sentences. At the end of each trial participants recalled the last words of the sentences they just read. They were instructed to remember the words in order and say them aloud to the experimenter, who marked the correctly recalled words on a response sheet. The next trial, with the next set size started after participants finished recalling.

After the reading span task, participants completed an online Spanish version of the LEAP-Q. Each experimental session lasted about 90 minutes.

\section{Data analysis procedures}

Reaction times faster than $300 \mathrm{~ms}$ were excluded from analysis. Data from 7 participants (9\% of sample) whose error rates exceeded $30 \%$ on either experimental or control trials were also excluded. Data from one participant were lost owing to a computer malfunction, leaving a final sample size of 71 participants. For the analyses with participants as the random factor, a 2 (related, unrelated) X 2 (homonym, non-homonym) X 2 (cognate, noncognate) within-subjects, repeated measures ANOVA was conducted. For analyses with items as the random factor, all three independent variables were between-items. Because the items were not randomly selected, but rather selected based on three attributes (cognate status, homonym status and relative frequency of homonym meanings), statements of significance are based on analyses with participants as the random factor. However, statistics from analyses performed with items as the random factor are also reported.

\section{Results}

See Table 4 for a summary of means and standard deviations. Overall, participants were faster to recognize targets that were related to primes $(M=860)$ relative to unrelated primes $\quad(M=916), \quad\left(F_{l}(1,71)=24.4, \quad M S E=18447\right.$, $p<.01) ;\left(F_{2}(1,186)=14.4, \mathrm{MSE}=147,132, p<.001\right)$. The interaction between relatedness and homonym status was also significant, $\left(\left(F_{I}(1,71)=5.5, M S E=10268\right.\right.$, $\left.p<.05) ;\left(F_{2}(1,186)=3.01, M S E=32, p>.05\right)\right)$. Followup, paired, t-tests revealed that, for unrelated prime-target pairs, recognition latencies of target words did not differ between homonym and non-homonym primes $(M=911$ and $M=921$ respectively), $t(71)=-.73, p>.05$. For related prime-target pairs, recognition latencies for target words were significantly longer when preceded by homonym primes relative to non-homonym primes ( $M=875.3$ and $M=845.4$ respectively), $t(71)=2.9$, $p<01$.

Participants made fewer errors on targets preceded by related primes $(M=3.7)$ relative to unrelated primes $(M=7.81), \quad\left(\left(F_{l}(1,71)=15.4, \quad M S E=106, \quad p<.01\right)\right.$; $\left.\left(F_{2}(1,186)=111, M S E=3,101, p<.05\right)\right)$. There was also a main effect of cognate status, reflecting participants' lower error rates on targets preceded by cognates $(M=5.3)$ than noncognates $(M=6.2)$, $\left(\left(F_{1}(1,71)=5.3, M S E=22, p<.05\right) ;\left(F_{2}(1,186)=1.6\right.\right.$, $M S E=45, p>.05))$. The main effect of cognate status was qualified by an interaction with relatedness, $\left(F_{I}(1,71)=1.63, M S E=22, p<.01\right) ;\left(F_{2}(1,186)=.93\right.$, $M S E=26.1, p>.05))$. Follow-up paired t-tests revealed that there was cognate facilitation only for related trials $(M$ cognates $=2.5 ; M$ noncognates $=4.8), t(71)=3.74$, $p<.01$. None of the other main effects or interactions were significant, all $p$ 's $>.05$.

To test whether access to subordinate meanings of cognate homonyms is facilitated relative to noncognate homonyms, recognition latencies and error rates from 


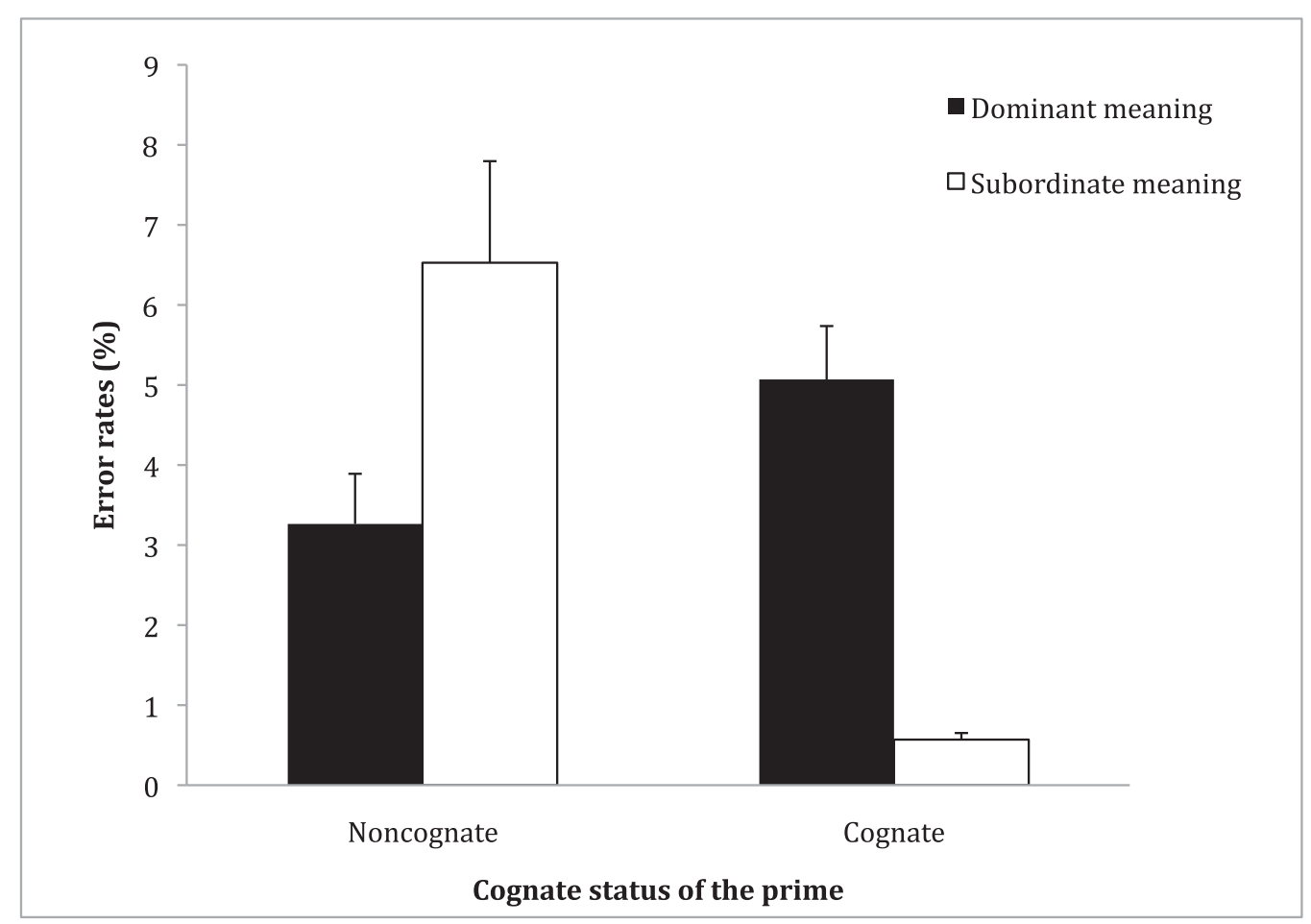

Figure 1. Percent error rates on targets related to either the dominant or subordinate meanings of cognate or noncognate homonym primes. Standard errors are represented in each figure by the error bars attached to each column.

the related trials were submitted to a 2 (cognate versus noncognate homonym prime) X 2 (subordinate versus dominant meaning) ANOVA.

\section{Reaction time data}

A main effect of cognate status was observed, $\left(F_{1}(1,71)=6.2, M S E=12082, p<.05\right) ;\left(F_{2}(1,73)=\right.$ $2.25, M S E=26,392, p>.05))$, reflecting a cost when the homonym prime was also a cognate $(M=891)$ versus a noncognate $(M=859)$. There was also a main effect of the meaning instantiated by the target, which revealed that participants were faster to recognize targets related to the dominant meaning of the homonym $(M=849)$, relative to the subordinate meaning $(M=901),\left(F_{1}(1,71)=20.3\right.$, $M S E=9314, p<.01) ;\left(F_{2}(1,73)=5.2, M S E=61,021\right.$, $p<.05)$. The interaction between cognate status and meaning instantiated by the target was not significant, $p>.05$.

\section{Error rate data}

The main effect of cognate status was significant, reflecting lower error rates when primes were cognate homonyms $(M=2.8)$, relative to noncognate homonyms $(M=4.9),\left(F_{1}(1,71)=9.2, M S E=33\right.$, $p<.01) ;\left(F_{2}(1,73)=3.3, M S E=87, p=.07\right)$. This was qualified by an interaction with meaning instantiated by the target, $\left(F_{1}(1,71)=30.2, M S E=36, p<.01\right)$; $\left(F_{2}(1,73)=5.1, M S E=134, p<.05\right)$. Follow-up paired t-tests revealed that, for noncognate homonym primes, participants made more errors when the targets instantiated the subordinate meaning $(M=6.5)$ relative to the dominant meaning $(M=3.3), t(71)=-3.3, p<.01$. When homonyms were cognates, on the other hand, participants made fewer errors on targets instantiating the subordinate meaning $(M=.57)$ relative to the dominant meanings $(M=5.1), t(71)=7.0, p<.01$ (See Figure 1$)$. This pattern in error rates supports the hypothesis that cross-language activation facilitates access to subordinate homonym meanings.

\section{Intercorrleations between predictors}

The analysis of intercorrelations between the predictors, on both reaction times and error rate data, reflected the somewhat interactive nature of the predictors. In reaction times, the cognate status impact score and WMC showed a medium size, negative correlation, $r=-.32, p<.01$, demonstrating that greater WMC was associated with a smaller influence of cognate status on lexical access. In the error rates, there was a small, negative correlation between the impact of cognate status impact score and access to subordinate meanings of L1 homonyms, $r=-.25$, $p<.05$. Thus, bilinguals who benefitted from cognate status were also less likely to make errors in identifying 
Table 5. Summary of multiple regression analysis predicting lexical decision performance for targets related to the subordinate meaning of homonym primes that were either cognates or noncognates in Experiment 1.

\begin{tabular}{|c|c|c|c|c|}
\hline & \multicolumn{4}{|c|}{ Access to subordinate meanings of L2 homonyms } \\
\hline & \multicolumn{2}{|c|}{ Noncognates } & \multicolumn{2}{|c|}{ Cognates } \\
\hline & Error rates & Reaction times & Error rates & Reaction times \\
\hline$R^{2}$ & $.26^{* *}$ & $.29^{* *}$ & $.30^{* *}$ & $.32^{* *}$ \\
\hline Predictor & $\beta$ & $\beta$ & $\beta$ & $\beta$ \\
\hline Impact of cognate status & $.23^{*}$ & .03 & $.29^{* *}$ & .10 \\
\hline Access to subordinate meanings of L1 homonyms & $.39^{* *}$ & $.55^{* *}$ & $.39^{* *}$ & $.57^{* *}$ \\
\hline Working memory capacity & .03 & .10 & $-.18^{\dagger}$ & .13 \\
\hline
\end{tabular}

Note. ${ }^{*} \mathrm{p}<.05 .{ }^{* *} \mathrm{p}<.01 .{ }^{\dagger} \mathrm{p}<.10$.

subordinate meanings of L1, Spanish homonyms. None of the other correlations were significant, all $p$ 's $>.05$.

\section{Analyses of the individual differences measures}

Two separate multiple regression analyses, for latency and error rate data, were conducted to assess the influence of the three individual differences measures (efficiency in access of subordinate L1 homonym meanings, WMC and cognate status impact score) on lexical decision performance for targets related to the subordinate meaning of the prime as a function of the prime's cognate status. For each of the regression analysis the three predictors were entered simultaneously in the first model.

\section{Noncognate homonym primes}

\section{Error rates}

The three predictors accounted for $26 \%$ of variance in error rates in identifying targets related to the subordinate meanings of noncognate homonym primes $\left(R^{2}=.26\right.$, $F(3,66)=7.5, M S E=83.12, p<.01)($ see Table 5). With all three variables in the model, the cognate status impact score and error rates in identifying $\mathrm{L} 1$ subordinate homonym meanings were significant predictors $(\beta=.23$, $t(66)=2.1, p<.05$ and $\beta=.39, t(66)=3.5, p<.01$, respectively). This indicates that for every one standard deviation increase in the cognate status impact score (reflecting an increase in cognate facilitation) there was a .23 increase in error rates, holding all other variables constant. In addition, for every one standard deviation decrease in error rates in identifying targets related to the subordinate meaning of $\mathrm{L} 1$ homonyms, there was a .39 decrease in error rates in identifying subordinate meanings of L2 homonyms, holding all other variables constant. Access to L1 subordinate meanings was the strongest predictor of error rates ( $\beta=.39$ for access to subordinate meanings of L1 homonyms, $\beta=.23$ for cognate status effects).

\section{Reaction time}

The three predictors accounted for about 29\% of variance in speed of responding to targets related to the subordinate meaning of noncognate homonyms, $\left(R^{2}=.29, F(3,66)=8.9, M S E=45747.7, p<.01\right)($ see Table 5). With all three variables in the model, only speed of accessing subordinate meanings of L1 homonyms was a significant individual predictor $(\beta=.55, t(66)=5.2$, $p<.01)$. Here, for every one standard deviation increase in speed of access to L1 homonym meanings, there was a .55 increase in time to identify L2 homonym meanings, while holding all other variables constant.

\section{Cognate homonyms}

\section{Error rates}

The three predictors accounted for $30 \%$ of variance in error rates when responding to targets related to the subordinate meaning of cognate homonyms, $\left(R^{2}=.30\right.$, $F(3,66)=9.3, M S E=.33, p<.01)($ see Table 5). With all three variables in the model, the cognate status impact score and error rates in identifying L1 subordinate meanings were significant, individual predictors of error rates $(\beta=.29, t(66)=2.7, p<01$ and $\beta=.39$, $t(66)=3.6, p<.01$, respectively). WMC only approached significance, $(\beta=-.18, t(66)=-1.7, p=.09)$. Here, for every one standard deviation increase in the cognate status impact score (reflecting a facilitation pattern) there was a .29 increase in error rates, while holding all other variables constant. Error rates in identifying L1 homonym meanings was the strongest predictor. For every one standard deviation decrease in error rates in identifying L1 homonym meanings there was a .39 decrease in error rates associated with identifying L2 cognate homonym meanings.

\section{Reaction time}

The three predictors accounted for about 32\% of variance in speed of access to targets related to the 
subordinate meaning of $\mathrm{L} 2$ cognate homonyms, $\left(R^{2}=.32\right.$, $F(3,66)=10.5, M S E=30004.7, p<.01)$ (see Table 5). Only speed of access to L1 subordinate homonym meanings was a significant, individual predictor $(\beta=.57$, $t(66)=5.5, p<.01)$, indicating that for every one standard deviation increase in time to identify L1 targets related to the subordinate meaning, there was a corresponding .57 increase in identification in the $\mathrm{L} 2$, while holding all other variables constant.

\section{Discussion}

The major finding from Experiment 1 was that the ability to identify L2 target words quickly and accurately related to subordinate meanings of homonym primes was best predicted by differences in speed and accuracy in identifying targets related to subordinate meanings in the L1. This finding supports the hypothesis that the same cognitive mechanism underlies ambiguity resolution in the L1 and L2. Individual differences in the cognate status impact score also emerged as a significant predictor of error rates. However, the relationship was in the opposite direction from the one predicted. A bigger cognate status impact score, reflecting a tendency towards cognate facilitation, was associated with an increase in error rates. One interpretation of this unexpected relationship is that greater reliance on lexical form was at the cost of attending to meaning. Lexical access of unambiguous cognates does not require resolving competition between two semantic representations. Thus, readers who relied more on lexical form showed facilitated performance for unambiguous cognates, but a cost when processing cognates with multiple meanings.

The lack of an observed predictive power of cognate status on reaction time may be due to the fact that the sample of cognates selected did not have an overall impact on reaction times for non-homonym trials, as reported in the ANOVAs. This in turn, is likely due to the fact that error trials are not included in analyses on reaction time. Finally, as predicted, individual differences in working memory span did not predict performance.

\section{Experiment 2}

The purpose of Experiment 2 was to examine whether the relative contributions of the individual difference factors examined in Experiment 1 would change when predicting processing time of L2 homonyms in a sentence context. We expected bilinguals' access to subordinate homonym meanings in the $\mathrm{L} 1$ to be a significant predictor of access to cognate and noncognate subordinate homonym meanings in the L2. We also predicted that individual differences in WMC would be a predictor of homonym processing time. Finally, we expected to observe only a limited role of the cognate status impact score since previous research has demonstrated a smaller impact of cross-language lexical activation in sentence context (e.g., Bultena, Dijkstra \& Van Hell, in press; Schwartz \& Kroll, 2006; Van Hell \& de Groot, 2008)

\section{Methods}

\section{Participants}

125 Spanish-English bilinguals were initially recruited from Introduction to Psychology courses at UTEP. After applying the same proficiency criteria as those of Experiment 1, data from 37 participants were excluded from the sample, a rate of $30 \%$. leaving a final sample of 88 .

\section{Proficiency measures}

The same subjective proficiency measure and inclusion criteria from Experiment 1 were used in Experiment 2. As a measure of objective proficiency, participants' English and Spanish total reading times of the non-homonym, noncognate (control) trials were used. Shorter reading times in one of the languages indicated higher proficiency in that language.

\section{Proficiency data}

Data from the LEAP-Q are summarized in Table 6. Participants reported acquiring English later than Spanish, $t(87)=-7.74, p<.01$. Participants also rated their proficiency (averaging across reading, speaking and comprehending) higher in Spanish $(M=8.9)$ than English $(M=7.5), t(87)=7.9, p<.01$. Additionally, participants were more exposed to Spanish $(M=58 \%)$ than English $(M=42 \%), t(87)=4.04, p<.01$, and spoke more in Spanish $(M=64 \%), t(84)=5.98, p<.01$. Participants' total reading times across neutral and biased sentences in the control condition (i.e. noncognate non-homonym) did not differ between Spanish $(M=363)$ and English $(M=389), t(87)=1.6, p>.05$. Taken together, these results suggest that, although bilinguals reported being more proficient in Spanish than English, in terms of reading they were similar across languages. In fact, bilinguals reported reading in English $(M=53 \%)$ just as frequently as in $\operatorname{Spanish}(M=47 \%), t(85)=1.34, p>.05$.

\section{Materials}

\section{Critical words}

The same set of homonyms and non-homonym controls from Experiment 1 were used.

\section{English stimulus sentences}

For each critical word two sentences were created: one in which the preceding context did not bias any meaning of the upcoming critical word, and one in which the 
Table 6. Self-rated proficiency, objective proficiency and language background of the Spanish-English bilinguals in Experiment 2.

\begin{tabular}{lcc}
\hline \hline & Self-rated proficiency measures from LEAP-Q & \\
\hline & Mean $(S D)$ & Mean $(S D)$ \\
& Spanish & English \\
\hline Speaking & $9.0(1.0)$ & $7.3(1.9)$ \\
Reading & $8.5(1.6)$ & $7.4(1.7)$ \\
Comprehending & $9.0(1.1)$ & $7.8(1.6)$ \\
& Percentage of time reported exposed to each language & \\
\hline & Mean $(S D)$ & Mean (SD) \\
& Spanish & English \\
\hline Total exposure & $57.5(18.3)$ & $42.5(17.8)$ \\
Reading & $53(21.2)$ & $47(21.4)$ \\
Speaking & $63.8(22.3)$ & $35.2(22.1)$ \\
& Age of acquisition of each language & \\
\hline & Mean $(S D)$ & Mean (SD) \\
& Spanish & English \\
\hline & $2.1(3.8)$ & $7.8(5.3)$ \\
\hline & Total reading times on control targets across neutral and biased contexts & \\
\hline & Mean (SD) & Mean (SD) \\
& Spanish & $389.3(149.7)$ \\
\hline
\end{tabular}

Table 7. Examples of English and Spanish sentence stimuli used in Experiment 2.

\begin{tabular}{llc}
\hline \hline Type of context & Homonym & English Stimuli \\
\cline { 2 - 4 } Neutral & $\begin{array}{c}\text { In excited anticipation she placed her hands on } \\
\text { the chest and thought of all the gold inside. }\end{array}$ & $\begin{array}{c}\text { It was not easy and it took several years to get the } \\
\text { cabinet to be composed of members from both } \\
\text { parties. }\end{array}$ \\
Subordinate biased & $\begin{array}{c}\text { The pirates stole the gold that was inside the } \\
\text { chest hidden in the sunken ship. }\end{array}$ & $\begin{array}{c}\text { The president was not happy with how the } \\
\text { members of his cabinet carried out their } \\
\text { business. }\end{array}$ \\
\hline Neutral & $\begin{array}{c}\text { Mi prima Hilda siempre pone un tipo de } \\
\text { guarnición en sus arreglos. }\end{array}$ & $\begin{array}{c}\text { Tomás dice que se va a vestir de murciélago para } \\
\text { la fiesta de disfraces. }\end{array}$ \\
& $\begin{array}{c}\text { A la estilista no le gusta usar ninguna guarnición } \\
\text { grande para los peinados de novia. }\end{array}$ & $\begin{array}{c}\text { Porque es un animal nocturno, el murciélago } \\
\text { solamente sale de noche. }\end{array}$ \\
\hline \hline
\end{tabular}

preceding context strongly biased the meaning (in the case of homonyms always the subordinate meaning). Biasing and neutral sentences were matched in length and in the number of words that preceded the target word. The same sentence manipulation was created for non-homonym, control words. In one third of the trials comprehension questions followed the presentation of the sentence to ensure that participants were reading for comprehension.
See Table 7 for an example of the sentence stimuli used in Experiment 2.

\section{Individual differences measures}

\section{Working memory measure}

As in Experiment 1, the measure of working memory capacity was obtained from the Reading Span task, which 
was performed in Spanish, participants' L1. Participants' span ranged from 1.5 to 4 , and the average was 2.3. Thus, participants in Experiment 2 also fell under the mid-span category.

\section{Meaning access in the L1}

To obtain a measure of access to L1 subordinate meanings, participants read Spanish sentences containing homonyms (syntactically unambiguous Spanish homonyms from Experiment 1) while their eye-movements were tracked. In these sentences the context preceding the appearance of the homonym either biased the subordinate meaning of the homonyms or was neutral $(\mathrm{n}=70)$. Control sentences containing non-homonyms were also created $(n=70)$; half of these were neutral and half were biased. We used First Fixation Durations (FFDs) and Gaze Durations (GDs) on Spanish homonym targets in neutral and biased contexts to predict FFDs and GDs on English homonym targets in their respective contexts. See Table 7 for sample sentences in Spanish.

\section{Measuring impact of cognate status on lexical access} Similar to Experiment 1, a difference score [(noncognate) - (cognate)] was calculated using the FFDs and GDs from the non-homonym sentence conditions as a measure of the impact of cognate status on lexical access for each participant. Higher scores indicated greater cognate facilitation.

\section{Apparatus}

An eye-tracking system (SR Research Ltd. Eyelink 1000) was used to monitor participants' eye-movements as they read the sentences. This system is used with a chin and forehead rest, and is a video-based tracker consisting of one desktop mounted camera. The spatial resolution is $0.01^{\circ}$ in pupil-only mode and the sampling rate is $1000 \mathrm{~Hz}$. Viewing was binocular, but data were collected in monocular mode, from the participants' dominant eye. The sentences were presented on the 17-inch Dell PC monitor. The camera set up includes three steps which are the camera adjustment, calibration, and validation. Camera adjustment ensures that participants' pupils can be captured by the cameras even when they look at the corners of the screen. In order to know precisely what subjects are looking at, a 9-point calibration and validation procedure was conducted to record the value that corresponds to each gaze position.

\section{Procedure}

Participants started with the eye-tracking sentence processing tasks. Each read practice sentences to get used to reading while his or her head was on the chin rest. Each trial started with a fixation point presented in the left side of the screen. Participants were instructed to fixate on the dot and then press the space bar on the computer keyboard to see the sentence. Sentences were presented left-flushed, in the middle of the screen. After participants read the sentence, they pressed the space bar again to go to the next sentence. The task was self-paced and participants were instructed to read each sentence thoroughly and attentively because, after some sentences, a comprehension question would be presented. Next, participants completed the same task in Spanish, following the same procedures.

Participants then completed the Reading Span task in Spanish and the LEAP-Q, which were identical to the reading span from Experiment 1 . The entire experimental session lasted about 90 minutes.

\section{Data Analysis Procedures}

The eye-tracking procedure allows for the analysis of different aspects of the eye-movement record that have been associated with different stages of reading comprehension. Because the focus of the study was on initial meaning access, we focused our analyses of individual differences factors on eye-tracking measures that tap into processes of lexical access: first fixation durations (FFD) and gaze duration (GD) (Rayner \& Pollatsek, 2006). The first fixation duration is the length, in milliseconds of the first fixation made on the target word the first time the eye lands on it, while GD is the summed duration of all fixations made on a word before moving right-ward (in the case of English). We also measured total reading times (TRT), but because we were most interested in measures of initial meaning access we only report them in Tables 6 and 8 . Data from 9 participants whose accuracy was lower than $80 \%$ on the follow-up comprehension questions were excluded from analyses, leaving a final sample of 79 . As with Experiment 1 , statements of significance are based on analyses by participants, and results from analyses with items as the random factor are reported for reference.

\section{Results}

\section{General effects of sentence context, homonym status and cognate status}

As reviewed earlier, the contextual bias of a sentence alters the time-course with which a subordinate meaning is activated. In the absence of any contextual bias, activation of the subordinate meaning lags behind that of the dominant and there is no direct competition between the two meanings early on in processing. However, when the context biases the subordinate, it's activated in an earlier time frame and competes with the dominant meaning. This incurs a cost in processing time. This has been termed the "subordinate bias effect" (Duffy et al., 1988). 
Table 8. Participants' mean FFDs GDs and TRTs on the English sentence-reading task.

\begin{tabular}{|c|c|c|c|c|c|c|c|c|}
\hline \multicolumn{9}{|c|}{ First Fixation Duration } \\
\hline & \multicolumn{4}{|c|}{ Neutral Context } & \multicolumn{4}{|c|}{ Biased Context } \\
\hline & \multicolumn{2}{|c|}{ Non-homonym } & \multicolumn{2}{|c|}{ Homonym } & \multicolumn{2}{|c|}{ Non-homonym } & \multicolumn{2}{|c|}{ Homonym } \\
\hline & Non-cognate & Cognate & Non-cognate & Cognate & Non-cognate & Cognate & Non-cognate & Cognate \\
\hline Mean & 220 & 224 & 219 & 236 & 215 & 218 & 228 & 222 \\
\hline SD & 39 & 35 & 38 & 47 & 33 & 35 & 39 & 39 \\
\hline \multicolumn{9}{|c|}{ Gaze Duration } \\
\hline Mean & 279 & 286 & 260 & 302 & 265 & 271 & 277 & 276 \\
\hline SD & 79 & 69 & 63 & 73 & 70 & 63 & 76 & 60 \\
\hline \multicolumn{9}{|c|}{ Total Reading Time* } \\
\hline Mean & 396 & 389 & 411 & 449 & 347 & 344 & 404 & 376 \\
\hline SD & 140 & 135 & 160 & 145 & 134 & 103 & 200 & 125 \\
\hline
\end{tabular}

*Significant effects on TRTs: Main effect of type of context, $F(1,78)=24.5, M S E=12241.9, p<.01$. Main effect of homonym status, $F(1,78)=21.4$, $M S E=12595.9, p<.01$.

We examined whether $\mathrm{L} 2$ readers would show a subordinate bias effect in their L2, and whether it would be different for cognate homonyms. We hypothesized that, when subordinate meanings were also cognates, activation would be accelerated. This would allow it to compete early on with the dominant meaning, even in the absence of contextual bias. In biasing contexts we hypothesized that the joint influences of context and co-activation would allow activation of the subordinate meaning to outpace that of the dominant, with no observable cost in processing time. Confirmation of this prediction would be consistent with the observed negative impact of homonym cognate status in Experiment 1. In both cases boosted activation of the subordinate meaning of a cognate causes it to compete earlier with the dominant meaning. When comprehending a sentence, this earlier competition is an advantage because at some point that subordinate meaning must be selected.

Mean FFDs and GDs were submitted to two separate 2 (context) X 2 (homonyms status) $\mathrm{X}$ 2 (cognate status) ANOVAs. Both factors were within-participants for $F_{1}$ analyses and betweenitems for $F_{2}$ analyses. The three-way interaction was significant for FFD $\left(F_{1}(1,78)=6.5, M S E=879\right.$, $p<.05) ;\left(F_{2}(1,56)=3.2, M S E=722, p=.08\right)$ and GD $\left(F_{1}(1,78)=5.9, M S E=2885, p<.05\right) ;\left(F_{2}(1,56)=1.3\right.$, $M S E=5,382, p>.05$ ) (see Table 8 for means across conditions and measures). Follow-up t-tests revealed that, in neutral contexts, processing times of cognate homonyms were longer than for cognate non-homonyms, which was significant in FFD, $t(78)=2.35, p<.05$, and approached significance in GD measures, $t(78)=1.84$, $p=.07$. FFD measures for noncognates, on the other hand, showed no difference between homonyms and nonhomonyms, $t(78)=0.5, p>.05$. Instead, this competition arose at a later stage, as reflected in GD, $t(78)=2.5$, $p<.05$. This provides support for the hypothesis that cross-language activation of a subordinate meaning accelerates its activation, allowing it to compete early on with the dominant meaning in the absence of a biasing context.

In biasing contexts, processing times for cognate homonyms and non-homonyms did not differ. This supports the hypothesis that the combination of context and cognate status allowed the subordinate meaning's activation to out-pace that of the dominant. Processing times for noncognates reflected the typical subordinate bias effect, with longer processing times for homonyms relative to non-homonyms in FFD measures, $t(78)=2.69$, $p<.05$.

\section{Intercorrelations between predictors}

The analysis of intercorrelations between the independent variables predicting the variables of interest in this study, FFDs and GDs for noncognate and cognate homonyms, indicated that the predictors were not correlated, all $p$ values $>.05$.

\section{Analyses of individual differences measures}

Multiple regression analyses with the three predictors entered simultaneously in the model were conducted to predict FFDs and GDs on cognate and noncognate homonyms across neutral and biasing sentence contexts. 


\section{Noncognate homonyms}

\section{Neutral contexts, FFD}

The three predictors accounted for $27 \%$ of variance in first fixation duration for noncognate homonyms in a neutral context, $\left(R^{2}=.27, F(3,75)=9.4, M S E=1110.4\right.$, $p<.01$ ) (see Table 9). Only FFD on L1 homonyms was a significant predictor $(\beta=.47, t(75)=4.8, p<.01)$. For every one standard deviation increase in FFDs on L1 homonyms in a neutral context there was a .47 increase in FFDs on L2 noncognate homonyms, while holding other variables constant. The cognate status impact score approached significance. The direction of the effect reflected that an increase in cognate facilitation was related to increased processing time of L2 noncognate homonyms, $(\beta=.18, t(75)=1.8, p=.08)$.

\section{Neutral context, GD}

The overall model accounted for about $11 \%$ of variance, $\left(R^{2}=.11, \quad F(3,75)=3.0, \quad M S E=3705, \quad p<.05\right) \quad($ see Table 9). Only GD for L1 homonyms was a significant predictor $(\beta=.33, t(75)=4.8, p<.01)$. For every one standard deviation increase in GDs on L1 homonyms in a neutral context there was a .33 increase in GDs on L2 noncognate homonyms, while holding other variables constant.

\section{Biasing contexts, FFD}

The overall model with the three variables did not explain significant variance, $\left(R^{2}=.08, F(3,75)=2.2\right.$, $M S E=1512.1, p>.05$ ) (see Table 9). Only FFDs for L1 homonyms was a significant predictor, indicating that for every one standard deviation increase in FFDs on L1 homonyms in a biased context, there was a .28 increase in FFDs on L2 noncognate homonyms in a biased context, while holding other variables constant, $(\beta=.28$, $t(75)=2.4, p<.05)$.

\section{Biasing context, GD}

The overall model did not explain significant variance, $\left(R^{2}=.06, F(3,75)=1.6, M S E=57061, p>.05\right) \quad($ see Table 9). As with FFD, when all three variables were included in the model, only GD for L1 homonyms was a significant predictor, indicating that for every one standard deviation increase in FFDs on L1 homonyms in a biased context there was a .24 increase in GDs on L2 noncognate homonyms in a biased context, while holding other variables constant, $(\beta=.24, t(75)=2.4, p<.05)$.

In sum, processing of noncognate homonyms in sentence context was primarily accounted for by individual differences in accessing homonym meanings in the L1.

\section{Cognate homonyms}

\section{Neutral contexts, FFD}

The three predictors accounted for about $17 \%$ of variance, $\left(R^{2}=.17, F(3,75)=5.1, M S E=1942.8, p<.01\right)($ see Table 9). Only FFDs to L1 homonyms was a significant predictor. For every one standard deviation increase in FFDs on L1 homonyms in a neutral context there was a .41 increase in FFDs on L2 cognate homonyms in a neutral context, while holding other variables constant, $(\beta=.41$, $t(75)=3.8, p<.01)$.

\section{Neutral contexts, $G D$}

The overall model accounted for about $19 \%$ of variance, $\left(R^{2}=.19, \quad F(3,75)=5.7, \quad M S E=4508, p<.01\right) \quad($ see Table 9). The strongest predictor was GDs for L1 homonyms. For every one standard deviation increase in GDs for L1 homonyms there was a .38 increase in GDs for L2 cognate homonyms $(\beta=.38, t(75)=3.5$, $p<.01)$. Individual differences in the cognate impact score also significantly predicted GDs. For every one standard deviation increase in the cognate effect score (i.e. greater cognate facilitation) there was a .21 increase in GD for L2 cognate homonyms $(\beta=.21, t(75)=3.8, p=.046)$. We did not expect cognate status to be a significant predictor of homonym processing in sentence context. However, the nature of the relationship is consistent with the hypothesis that cognate status allows for accelerated access to subordinate meanings. Specifically, readers who reaped a greater benefit of cognate status also were able more quickly to activate a cognate subordinate meaning of a homonym in sentence context, causing longer GDs in neutral contexts.

\section{Biasing contexts, FFD}

The three predictors explained about $26 \%$ of the variance, $\left(R^{2}=.26, F(3,75)=8.9, M S E=1194.2, p<.01\right) \quad($ see Table 9). With all three variables in the model, both FFDs on L1 homonyms and working memory span were significant predictors. For every one standard deviation increase in FFDs on L1 homonyms in a biased context there was a 49 increase in FFDs on L2 cognate homonyms in a biased context, $(\beta=.49, t(75)=4.9, p<.01)$. For every one standard deviation increase in working memory there was a .26 increase in FFDs on L2 cognate homonyms, $(\beta=.26, t(75)=2.6, p<.05)$.

\section{Biasing contexts, $G D$}

The three individual differences factors did not explain a significant amount of variance $\left(R^{2}=.05, F(3,75)=1.4\right.$, $M S E=3581, p>.05)$, nor did any of the predictors alone. See Table 9.

In sum, for cognate homonyms, individual differences in accessing homonyms meanings in the L1 emerged as the most consistent predictor. The cognate impact score 
Table 9. Summary of multiple regression analysis performed in Experiment 2 predicting FFD and GD on L2 cognate and noncognate homonyms across neutral and biasing contexts.

\begin{tabular}{|c|c|c|c|c|}
\hline \multicolumn{5}{|c|}{ First Fixation Duration } \\
\hline & \multicolumn{2}{|c|}{ Noncognates } & \multicolumn{2}{|c|}{ Cognates } \\
\hline & Neutral context & Biased context & Neutral context & Biased context \\
\hline$R^{2}$ & .27 & $.08^{\dagger}$ & $.17^{* *}$ & $.26^{* *}$ \\
\hline Predictor & $\beta$ & $\beta$ & $\beta$ & $\beta$ \\
\hline Degree of cross-language activation & .18 & -.01 & -.05 & .02 \\
\hline Access to subordinate meanings of $\mathrm{L} 1$ homonyms & $.48^{* *}$ & $.28^{*}$ & $.41^{* *}$ & $.49^{* *}$ \\
\hline Working memory capacity & .04 & .12 & .11 & $.26^{*}$ \\
\hline \multicolumn{5}{|c|}{ Gaze Duration } \\
\hline$\overline{R^{2}}$ & $.11^{*}$ & .06 & $.19^{* *}$ & .05 \\
\hline Degree of cross-language activation & .05 & .09 & $.21^{*}$ & .06 \\
\hline Access to subordinate meanings of L1 homonyms & $.33^{* *}$ & $.24^{*}$ & $.38^{* *}$ & .19 \\
\hline Working memory capacity & .15 & .07 & -.10 & .17 \\
\hline
\end{tabular}

Note. ${ }^{*} \mathrm{p}<.05 .{ }^{* *} \mathrm{p}<.01 .{ }^{\dagger} \mathrm{p}<.10$

predicted processing time in neutral contexts while $\mathrm{WMC}$ predicted processing time in biasing contexts.

\section{Discussion}

In summary, the results from Experiment 2 converge with those of Experiment 1; access to subordinate meanings of L1 homonyms was the most reliable and strongest predictor of access to subordinate meanings of L2 homonyms. This was true for both neutral and biased sentence contexts, as well as for both cognate and noncognate homonyms. This is further evidence that ambiguity resolution relies on the same cognitive process for both of a bilingual's languages. Greater working memory capacity was associated with longer first fixation durations on cognate homonyms in biasing contexts. This is likely due to the fact that readers with greater working memory resources are able to activate subordinate meanings early (early enough to influence first fixations) even before the bias in the biasing context becomes evident. Activation of the subordinate meaning incurs a cost from competing with the dominant meaning, and that is why those with higher capacity had longer processing times. As predicted, the cognate status impact score was limited, only approaching significance for noncognate homonyms in neutral sentence contexts.

\section{General discussion}

\section{Individual differences in access to L1 meanings}

In the present study we used processing of L1 homonyms in a lexical decision task (Experiment 1) and a sentence comprehension task (Experiment 2) as measures of the cognitive general skills of enhancement and suppression that are needed to access target homonym meanings. Since these are cognitive-general skills, we predicted that performance on these L1 tasks would be a reliable predictor of accessing subordinate meanings in the L2. Across both experiments, individual differences in performing the L1 tasks were a consistent predictor of subordinate meaning access in the L2. This was the case for noncognate and cognate homonyms and in single-word and sentence contexts. This result supports the assumption that, for bilinguals, accessing homonym meanings relies on the same cognitive skills across languages. This cognitive-general account can explain why L1 homonym processing was so closely related to L2 homonym processing; the ability to access subordinate meanings (e.g., enhancement of appropriate meanings) is not dependent on the language of processing. Future studies should examine how access to these mechanisms is influenced by language proficiency.

\section{Individual differences in working memory capacity}

The Daneman and Carpenter task was used as a measure of the working memory resources available for simultaneous holding and processing of information. We expected this measure to predict homonym processing time in sentence context. Performance on this task was associated with longer first fixation durations of cognate homonyms in biasing contexts. First fixation durations reflect the earliest stages of lexical access (Rayner \& Pollatsek, 2006). Thus, only bilinguals with higher WMC were able to activate the multiple meanings of the homonyms early enough for the competition to be manifest in FFD. This is convergent with monolingual studies in which differences in WMC were 
implicated with activation of homonym meanings (e.g., Miyake et al., 1994). This finding also demonstrates that $\mathrm{WMC}$ is another factor that influences the automaticity of homonym meaning activation in the L2, in addition to L2 proficiency (Frenck-Mestre \& Prince, 1997).

We did not expect such a limited influence of working memory. One possible reason is that the WMC task and sentence task were performed in different languages. Even highly-proficient bilinguals have lessautomatized skills in lexical access in their L2 relative to the L1. A differential recruitment of automatized versus non-automatized processes may have decreased the relationship between the two tasks. Partial support of this interpretation is the fact that WMC was related to first fixation durations on cognate homonyms in biasing contexts. Lexical access in this condition may have approximated the more-automatized processes of L1 lexical access due to the combined facilitative effects of cognate status and sentential bias.

\section{Individual differences in cognate status effects on lexical access}

To measure individual differences in the effect of cognate status on lexical access we calculated the difference in processing time and accuracy in identifying cognates versus noncognates in Experiment 1 and the difference in first fixation and gaze duration on cognates versus noncognates in Experiment 2. This score was predictive of accuracy in the lexical decision task of Experiment 1 and processing time in the neutral sentences of Experiment 2. The fact that the impact of this variable was only evident in primed lexical-decision and in neutral sentence contexts is consistent with our initial predictions and convergent with research demonstrating greater effects of cross-language activation in isolated word recognition tasks and neutral sentence contexts (e.g., Libben \& Titone, 2009; Schwartz \& Kroll, 2006; Van Hell \& de Groot, 2008). Interestingly, the relationship was in the opposite direction as predicted in both experiments: Readers who were more accurate in the lexical-decision task (Experiment 1) or more efficient in reading homonyms (Experiment 2) were less affected by cognate status. This finding converges with two recent studies on bilingual lexical access in sentence context. In those studies, bilinguals with higher L2 proficiency or earlier L2 age of acquisition were less likely to show a cognate facilitation effect in their processing times (Libben \& Titone, 2009; Pivneva, Mercier \& Titone, in press). The authors point out that less proficient bilinguals may show greater cognate facilitation because of a larger discrepancy in the functional frequency between cognates and noncognates, with the latter being considerably lower (Pivneva et al., in press). However, this is not sufficient to account for the present results, since a determinant in performance was also observed when processing cognate homonyms. Differences in lexical quality can be incorporated to account better for the negative relationship between processing of unambiguous cognates with ambiguous cognates. Bilinguals for whom noncognates were of lower functional frequency also had poorer quality lexical representations of L2 words. This impeded their ability to activate quickly the multiple meanings of L2 homonyms. Thus, form overlap does not benefit lexical disambiguation in the absence of lexical expertise.

\section{General effects of cross-language activation on bilingual ambiguity resolution}

In the present study a modified subordinate effect was observed for the bilingual readers in Experiment 2. Specifically, there was evidence that subordinate meanings of homonyms that were also cognates were activated at an earlier time frame than noncognate subordinate meanings. As a consequence, a subordinate bias effect for cognates was observed in first fixation durations in prior-neutral contexts and no competition was observed at all in prior-biasing contexts. This pattern diverges from the subordinate bias effect typically observed with monolinguals. For monolinguals, in the absence of a biasing context, the subordinate meaning of a homonym is not activated sufficiently to compete with the dominant meaning prior to the completion of lexical access. Rather, the cost from this competition is observed in post lexical access processing, captured in gaze duration and/or total reading time. The distinct subordinate bias effect pattern observed for cognate homonyms in the present study underscores the fact that cross-language activation can fundamentally alter the time-course of lexical competition in ways that will not be observed with monolingual readers.

\section{Conclusion}

The present studies reveal that at least three individual difference factors play a role in bilingual lexical disambiguation, or more specifically, in bilingual access to subordinate meanings in the L2. Homonym processing in the $\mathrm{L} 1$ emerged as the most reliable predictor. This is a new finding and supports the hypothesis that the ability to select appropriate meanings of homonyms is a processing skill that can be generalized across languages. Cognate status effects on lexical access, our new measure of cross-language activation as an individual difference factor, seem to be a more important factor in single-word contexts. This finding is convergent with existing research demonstrating stronger cross-language activation effects in single-word contexts than in sentence contexts (e.g., Bultena et al., in press; Schwartz \& Kroll, 2006; Van Hell \& de Groot, 2008). Working memory capacity had 
a limited effect on access to L2 subordinate meanings. This may be because the focus of the present study was on early lexical processing, as captured by the primed lexical decision task as well as the first fixation and gaze durations on homonyms. Working memory capacity may affect later stages of processing, such as integration of homonym meanings into a sentence.

\section{References}

Andrews, S. (2012). Individual differences in skilled visual word recognition and reading: The role of lexical quality. In J. Adelman S. (Ed.), Visual word recognition. meaning and context, individuals and development. (2nd ed., pp. 151172). New York, NY: Psychology Press.

Andrews, S., \& Bond, R. (2009). Lexical expertise and reading skill: Bottom-up and top-down processing of lexical ambiguity. Reading and Writing, 22 (6), 687-711. doi: 10.1007/s11145-008-9137-7

Andrews, S., \& Lo, S. (2012). Not all skilled readers have cracked the code: Individual differences in masked form priming. Journal of Experimental Psychology: Learning, Memory, and Cognition, 38 (1), 152-163. doi: $10.1037 / \mathrm{a} 0024953$

Arêas da Luz Fontes, A.B. \& Schwartz, A.I. (2011). The effects of working memory capacity on cross-language activation during lexical disambiguation. Bilingualism: Language \& Cognition, 14 (3), 360-370.

Bell, L. C., \& Perfetti, C. A. (1994). Reading skill: Some adult comparisons. Journal of Educational Psychology, 86 (2), 244-255.

Beretta, A., Fiorentino, R., \& Poeppel, D. (2005). The effects of homonymy and polysemy on lexical access: An MEG study. Cognitive Brain Research, 24 (1), 57-65.

Bultena, S., Dijkstra, T., \& Van Hell, J. G. (in press). Cognate and word class ambiguity effects in noun and verb processing. Language and Cognitive Processes.

Chwilla, D. J., \& Kolk, H. H. J. (2003). Event-related potential and reaction time evidence for inhibition between alternative meanings of ambiguous words. Brain and Language, 86 (2), 167-192.

Daneman, M. \& Carpenter, P. A, (1980). Individual differences in working memory and reading. Journal of Verbal Learning and Verbal Behavior, 19, 450-466.

Degani, T., \& Tokowicz, N. (2010). Ambiguous words are harder to learn. Bilingualism: Language and Cognition, 13, 299314.

De Groot, A. M. B. \& Keijzer, R. (2000), What Is Hard to Learn Is Easy to Forget: The Roles of Word Concreteness, Cognate Status, and Word Frequency in Foreign-Language Vocabulary Learning and Forgetting. Language Learning, $50,1-56$

Dijkstra, A. F. J., Grainger, J., \& Van Heuven, W. J. B. (1999). Recognition of cognates and interlingual homographs: The neglected role of phonology. Journal of Memory and Language, 41 (4), 496-518

Dijkstra, A., \& Van Hell, J. (2003). Testing the Language Mode hypothesis using trilinguals. International Journal of Bilingual Education and Bilingualism, 6, 2-16.
Dijkstra, T., Miwa, K., Brummelhuis, B., Sappelli, M., \& Baayen, H. (2010). How cross-language similarity and task demands affect cognate recognition. Journal of Memory and Language, 62 (3), 284-301. doi:10.1016/j.jml.2009.12.003

Dixon, P., \& Twilley, L. C. (1999). Context and homograph meaning resolution. Canadian Journal of Experimental Psychology, 53 (4), 335-346.

Duffy, S, Morris, R.K. \& Rayner, K. (1988). Lexical ambiguity and fixation times in reading. Journal of Memory and Language, 27, 429-446.

Duyck, W., Van Assche, E., Drieghe, D., \& Hartsuiker, R. J. (2007). Visual word recognition by bilinguals in a sentence context: Evidence for nonselective lexical access. Journal of Experimental Psychology: Learning, Memory, and Cognition, 33 (4), 663-679.

Elston-Güttler, K. E. (2000). An enquiry into cross-language lexical-conceptual relationships and their effect on L2 lexical processing. $\mathrm{PhD}$ dissertation, University of Cambridge.

Elston-Güttler, K. E., Gunter, T. C., \& Kotz, S. A. (2005). Zooming into L2: Global language context and adjustment affect processing of interlingual homographs in sentences. Cognitive Brain Research, 25 (1), 57-70.

Frenck-Mestre, C. \& Prince, P. (1997). Second language autonomy. Journal of Memory and Language, 37 (4), 481501.

Gernsbacher, M. A. (1990). Language comprehension as structure building. Hillsdale, NJ, England: Lawrence Erlbaum Associates, Inc.

Gernsbacher, M. A., Varner, K. R., \& Faust, M. (1990). Investigating differences in general comprehension skill. Journal of Experimental Psychology: Learning, Memory, and Cognition, 16, 430-445.

Gernsbacher, M. A. (1991). Cognitive processes and mechanisms in language comprehension: The structure building framework. In G. H. Bower (Ed.), The psychology of learning and motivation: Advances in research and theory, vol. 27. (pp. 217-263). San Diego, CA: Academic Press, Inc.

Gernsbacher, M. A., \& Faust, M. (1995). Skilled suppression. In F. N. Dempster (Ed.): Interference and inhibition in cognition (pp. 295-327). San Diego, CA: Academic Press, Inc.

Gernsbacher, M. A. (1997a). Attenuating interference during comprehension: The role of suppression. In D. L. Medin (Ed.), (1997). The psychology of learning and motivation: Advances in research and theory, vol. 37 (pp. 85-104). San Diego, CA: Academic Press.

Gernsbacher, M. A. (1997b). Two decades of structure building. Discourse Processes, 23 (3), 265-304.

Gernsbacher, M. A., Robertson, R. R. W., \& Werner, N. K. (2000). The costs and benefits of meaning. In D. S. Gorfein's (Ed.) On the consequences of meaning selection. APA Books, Washington, D.C.

Gernsbacher, M. A., \& St. John, M.F. (2001). Modeling suppression in lexical access. In: Gorfein, D.S. (Ed.), On the Consequences of Meaning Selection: Perspectives on Resolving Lexical Ambiguity. American Psychological Association, Washington, DC, pp. 47-65. 
Gollan, T. H., Forster, K. I., \& Frost, R. (1997). Translation priming with different scripts: Masked priming with cognates and noncognates in Hebrew English bilinguals. Journal of Experimental Psychology: Learning, Memory, and Cognition, 23, 1122-1139.

Gottlob, L. R., Goldinger, S. D., Stone, G. O., \& Van Orden, G. C. (1999). Reading homographs: Orthographic, phonologic, and semantic dynamics. Journal of Experimental Psychology: Human Perception and Performance, 25, 561574.

Gunter, T. C., Wagner, S. \& Friederici, A. D. (2003). Working memory and lexical ambiguity resolution as revealed by ERP's: a difficult case for activation theories. Journal of Cognitive Neuroscience, 15, 643-657.

Hino, Y., Lupker, S. J., \& Pexman, P. M. (2002). Ambiguity and synonymy effects in lexical decision, naming, and semantic categorization tasks: Interactions between orthography, phonology, and semantics. Journal of Experimental Psychology: Learning, Memory, and Cognition, 28 (4), 686-713.

Hoshino, N., \& Kroll, J. F. (2008). Cognate effects in picture naming: Does cross-language activation survive a change of script? Cognition, 106 (1), 501-511. doi:10.1016/j.cognition.2007.02.001

Klepousniotou, E. (2002). The processing of lexical ambiguity: Homonymy and polysemy in the mental lexicon. Brain and Language, 81 (1-3), 205-223.

Kroll, J. P., \& Stewart, E. (1994). Category interference in translation and picture naming: Evidence for asymmetric connections between bilingual memory representations. Journal of Memory and Language, 33, 149-174.

Lemhöfer, K., \& Dijkstra, T. (2004). Recognizing cognates and interlingual homographs: Effects of code similarity in language-specific and generalized lexical decision. Memory and Cognition, 32 (4), 533-550.

Lemhöfer, K., Dijkstra, T., \& Michel, M. C. (2004). Three languages, one ECHO: Cognate effects in trilingual word recognition. Language and Cognitive Processes, 19 (5), 585-611.

Libben, M. R. \& Titone, D. A. (2009). Bilingual lexical access in context: Evidence from eye movements during reading. Journal of Experimental Psychology, 35 (2), 381-390.

Marian, V., Blumenfeld, H. K., \&Kaushanskaya (2007). The Language Experience And Proficiency Questionnaire (LEAP-Q): Assessing language profiles in bilinguals and multilinguals. Journal of Speech, Language and Hearing Research, 50, 940-967.

Miyake, A., Just, A. M. \& Carpenter, P. A. (1994) Working memory constraints on the resolution of lexical ambiguity: Maintaining multiple representations in neutral contexts. Journal of Memory and Language, 33, 175-202.

Nelson, D. L., McEvoy, C. L., \& Schreiber, T. A. (1998). The University of South Florida word association, rhyme, and word fragment norms. http://www.usf.edu/FreeAssociation/.

Nievas, F., \& Mari Beffa, P. (2002). Negative priming from the non-selected meaning of the homograph. British Journal of Psychology, 93 (1), 47-66.
Pexman, P. M. \& Lupker, S. J. (1999). Ambiguity and visual word recognition: Can feedback explain both homophone and polysemy effects? Canadian Journal of Experimental Psychology, 53, 323-334.

Pivneva, I., Mercier, J. \& Titone, D. (in press). Executive control modulates cross-language lexical activation during L2 Reading: Evidence from eye movements. Journal of Experimental Psychology: Learning, Memory and Cognition.

Rayner, K., \& Pollatsek, A. (2006). Eye-movement control in reading. In M. J. Traxler, \& M. A. Gernsbacher (Eds.), Handbook of psycholinguistics (2nd ed., pp. 613-658) Academic Press.

Rodd, J., Gaskell, G., \& Marslen Wilson, W. (2002). Making sense of semantic ambiguity: Semantic competition in lexical access. Journal of Memory and Language, 46 (2), 245-266.

Schwartz, A. I., Kroll, J. F., \& Diaz, M. (2007). Reading words in Spanish and English: Mapping orthography to phonology in two languages. Language and Cognitive Processes, 22 (1), $106-29$.

Schwartz, A. I. \& Kroll, J. (2006) Bilingual lexical activation in sentence context. Journal of Memory and Language, 55 (2), 197-212.

Schwartz, A. I., Yeh, L. \& Shaw, M. (2008). Lexical representation of second language words: Implications for second language vocabulary acquisition and use. The Mental Lexicon, 3 (3), 309-324.

Segalowitz, N., \& Hulstijn, J. (2005). Automaticity in bilingualism and second language learning. In A. M. B. de Groot (Ed.), Handbook of bilingualism: Psycholinguistic approaches. (pp. 371-388). New York, NY US: Oxford University Press.

van Gelderen, A., Schoonen, R., de Glopper, K., Hulstijn, J., Simis, A., Snellings, P., \& Stevenson, M. (2004). Linguistic knowledge, processing speed, and metacognitive knowledge in first- and second-language reading comprehension: A componential analysis. Journal of Educational Psychology, 96 (1), 19-30.

van Gelderen, A., Schoonen, R., Stoel, R. D., de Glopper, K., \& Hulstijn, J. (2007). Development of adolescent reading comprehension in language 1 and language 2: A longitudinal analysis of constituent components. Journal of Educational Psychology, 99 (3), 477-491.

van Hell, J. G., \& de Groot, Annette M. B. (2008). Sentence context modulates visual word recognition and translation in bilinguals. Acta Psychologica, 128 (3), 431-451.

Van Orden, G.C. (1987). A rows is a rose: Spelling, sound and reading. Memory and Cognition, 15 (3), 181-198.

Walter, C. (2007). First- to second-language reading comprehension: not transfer, but access. International Journal of Applied linguistics, 17, 14-37.

Yap, M. J., Balota, D. A., Sibley, D. E., \& Ratcliff, R. (2012). Individual differences in visual word recognition: Insights from the english lexicon project. Journal of Experimental Psychology: Human Perception and Performance, 38 (1), 53-79. doi:10.1037/a0024177 